\title{
Virulence of Listeria spp.: course of infection in resistant and susceptible mice
}

\author{
TRYFONIA MAINOU-FOWLER, A. P. MACGOWAN* and R. POSTLETHWAITE
}

Departments of Bacteriology and "Pathology, University of Aberdeen, Medical School, Foresterhill, Aberdeen $A B 92 Z D$

\begin{abstract}
Summary. The virulence of representative strains of the five species of Listeria monocytogenes sensu lato was compared in C57BL/6 and BALB/c mice in terms of LD50 values and of bacterial growth kinetics and histological changes in mouse livers. L. monocytogenes sensu stricto and L. ivanovii showed relatively low LD50 values and much bacterial growth for 2-3 days before viable counts declined. Histological changes in L. ivanovii infection resembled those caused by L. monocytogenes, with early development of neutrophil-rich micro-abscesses and hepatocyte necrosis followed by macrophage infiltration and formation of granulomas. By contrast, $L$. innocua, $L$. welshimeri and $L$. seeligeri were almost entirely avirulent as shown by high LD50 values, early elimination of viable bacteria and no evidence of growth. Histological changes consisted only of slight, transient infiltration of the liver with neutrophils. Both groups of bacteria were seen infrequently in Kupffer cells early in infection, but only the highly virulent species appeared to replicate. LD50 values for L. monocytogenes and $L$. ivanovii were (10-20)-fold greater, and for the less virulent bacteria at least two-fold greater, in C57BL/6 than in BALB/c mice. This difference in host susceptibility was not reflected in detectable histological differences between the two mouse strains.
\end{abstract}

\section{Introduction}

Organisms of the genus Listeria are widespread in nature; they are found in animals, birds and man (Seeliger and Jones, 1986). Listeria monocytogenes sensu lato has been classified into five species on the basis of DNA homology (Rocourt et al., 1982) and contains at least 16 serovars. The genomic distinction correlates with phenotypic differences based on pathogenicity for mice (Rocourt et al., 1983a), haemolytic activity and carbohydrate fermentation reactions (Rocourt et al., 1983b). L. monocytogenes sensu stricto (hereafter referred to as L. monocytogenes) causes severe opportunistic infections in man and animals (Ralovich, 1984), L. ivanovii is preferentially pathogenic for sheep, and L. innocua, L. welshimeri and L. seeligeri are generally considered to be avirulent (Seeliger and Jones, 1986).

The facultative intracellular pathogen, L. monocytogenes, has been widely used for the study of cell-mediated immunity in infection (North, 1981 ; Bortolussi et al., 1984; Kaufmann,

Received 30 Oct. 1987; revised version accepted 16 Mar. 1988.
1984). Three clear-cut stages are seen when this organism is injected intravenously into mice (Mitsuyama et al., 1978). Firstly, $90 \%$ of the inoculum is cleared from the blood by liver Kupffer cells and, within $6 \mathrm{~h}, 90 \%$ of these bacteria are killed. During the next 2-3 days, residual organisms grow abundantly, despite pronounced focal accumulations firstly of neutrophil polymorphs (PMNs) and then of mononuclear phagocytes (Mandel and Cheers, 1980). In surviving animals, immune $T$ cells quench the infection in its final phase through macrophage (MP) activation. Despite their early prominence, PMNs appear to have no role in bacterial killing in vivo (Mitsuyama et al., 1978; Tatsukawa et al., 1979) and, indeed, bacteria are eliminated in the third stage of the hepatic infection as PMNs are replaced by MP-rich granulomas.

In recent years, genetically determined differences in innate resistance to $L$. monocytogenes have been found in inbred strains of mice (Cheers and McKenzie, 1978; Kongshavn, 1985) that can be attributed neither to PMNs nor to natural killer (NK) cells (Skamene and Kongshavn, 1983). After similar uptake of inoculum bacteria by Kupffer cells of both resistant and susceptible mice (Cheers 
et al., 1978), relative susceptibility is expressed during the second stage of infection, before the onset of acquired immunity, by impaired mobilisation of inflammatory MPs (Gervais et al., 1984; Czuprynski et al., 1985) or by reduced listericidal capacity of otherwise adequate cellular infiltrates (Czuprynski et al., 1985; Wood et al., 1986).

This general description of listerial pathogenicity was extended by Kaufmann (1984) in a study which determined the capacity of different serotypes of intravenously-inoculated listeriae to persist for several days in the spleens of $\mathrm{C} 57 \mathrm{BL} / 6$ mice. Persisters were able to induce strong, cross-reactive, $\mathrm{T}$ cell-mediated immunity. By contrast, organisms that were rapidly eliminated (non-persisting strains) were unable to induce effective cellular immune responses, although they expressed antigenic epitopes that were recognised by immune T cells.

No studies have yet compared patterns of infection by representatives of all five Listeria spp. in genetically resistant and susceptible mice. Accordingly, and as a preliminary to detailed studies of listerial virulence determinants in relation to mechanisms of early host resistance, we have performed such experiments in terms of bacterial growth kinetics and histology in the livers of intravenously-infected C57BL/6 and BALB/c mice.

\section{Materials and methods}

\section{Sources and characterisation of bacteria and tests for haemolysis}

Known serotypes of Listeria were obtained from Professor H. P. R. Seeliger (Institute of Hygiene and Microbiology, University of Würzburg, Federal Republic of Germany), Dr A. G. Taylor (Central Public Health Laboratory, Colindale, London) and $\mathrm{Dr}$ J. Rocourt (Institut Pasteur, Paris, France). Other strains were isolated in the Department of Bacteriology, University of Aberdeen, and serotyped at the Central Public Health Laboratory, Colindale, London. All were confirmed or initially identified as L. monocytogenes sensu lato (Rocourt et al., 1982) by the criteria of Seeliger and Höhne (1979). They were further examined for species-specific characteristics-in particular for fermentation of D-xylose, Lrhamnose and $\alpha$-methyl-D-mannoside (Rocourt et al., $1983 \mathrm{~b}$ ), for the presence (and zone diameter) of $\beta$ haemolysis around colonies after incubation for $24 \mathrm{~h}$ at $37^{\circ} \mathrm{C}$ on $5 \%$ sheep-blood agar, and by the CAMP test. The CAMP test was performed according to adaptations for listeriae (Groves and Welshimer, 1977; Fraser, 1962) of a test originally described for Group-B streptococci by Christie et al (1944); it detects Listeria species-related accentuated haemolysis in the neighbourhood of growth of $\beta$-lysin-producing Staphylococcus aureus or Rhodococ- cus equi. Based on these tests, 13 strains of Listeria, of different serotypes and representative of all five species, were selected for virulence studies.

Cultures of the Oxford strain of $S$. aureus and of $R$. equi NCTC 1621 were obtained from Dr D. R. Fenlon (Bacteriology Division, The North of Scotland College of Agriculture, Aberdeen).

\section{Mice}

BALB/c and C57BL/6 mice, raised under specified pathogen-free conditions, were used shortly after delivery to a conventional animal house when 8-12 weeks old and weighing $22-25 \mathrm{~g}$. They were fed pellets of CRM mouse diet (Labsure, Manea, Cambridgeshire) and water ad libitum.

\section{Virulence studies}

For LD50 experiments, bacteria were cultured directly from freeze-dried stocks. However, for strain ABl of $L$. monocytogenes in these experiments, and for all bacteria in the growth experiments, cultures were prepared from infected spleen homogenates after a single passage in BALB/c mice. Suspensions of bacteria grown in tryptose phosphate broth at $37^{\circ} \mathrm{C}$ for $18 \mathrm{~h}$ were assayed spectrophotometrically and viable counts were confirmed retrospectively by the method of Miles et al. (1938). LD50 values were determined by the method of Reed and Muench (1938) on the basis of mortality scored 10 days after the intravenous inoculation of five groups of five mice with 10-fold decreasing doses of viable bacteria. Patterns of bacterial growth in mouse livers were determined after injection into the tail vein of doses of viable bacteria approximating the LD50 for BALB/c mice. At intervals after infection, livers from groups of four or five mice were removed aseptically, individually homogenised in Tris buffer $(0.05 \mathrm{M}, \mathrm{pH} 7.4)$ and the numbers of viable bacteria in the homogenates determined, after inoculating 10-fold dilutions on to bloodagar plates, by the method of Miles et al. (1938).

\section{Histological evaluation}

After gross examination, portions of mouse livers were fixed in $10 \%$ neutral buffered formalin and embedded in paraffin. Sections were cut at $5 \mu \mathrm{m}$ and stained with haematoxylin and eosin and by Gram's method.

\section{Results}

\section{Cultural and biochemical features of Listeria species}

The 13 strains of Listeria chosen for virulence studies were gram-positive, non-spore-forming bacilli which were motile at room temperature but not at $37^{\circ} \mathrm{C}$. They produced catalase but not oxidase or urease, hydrolysed aesculin, and gave positive 
Voges-Proskauer and methyl red reactions. None reduced nitrate to nitrite. All produced acid but not gas from glucose, salicin and trehalose and none produced acid from mannitol. All were agglutinated by listeria polyvalent $\mathrm{O}$ antiserum (Difco). Accordingly they were considered L. monocytogenes sensu lato (Seeliger and Höhne, 1979; Rocourt et al., 1982) and speciated by tests for haemolysis and biochemical reactions (table) according to the criteria of Rocourt et al. (1983b).

\section{LD50 values}

There was no sex-related difference in LD50 values of $L$. monocytogenes SLCC 2540, type 3b, for either strain of mouse $\left(5.7 \times 10^{5} \mathrm{cfu}\right.$ for both male and female BALB/c and $6.2 \times 10^{6}$ and $6.1 \times 10^{6} \mathrm{cfu}$ for male and female C57BL/6 mice respectively). Consequently, mixed-sex populations were used for the ensuing experiments.

LD50 values for the 13 Listeria strains (table) showed a clear distinction between those of the highly virulent species, L. monocytogenes and $L$. ivanovii, on the one hand and those of the almost avirulent species, L. innocua, L. welshimeri and $L$. seeligeri, on the other. L. monocytogenes serotypes showed the greatest capacity to kill and also showed variations in lethality of up to 16-fold or 6fold, depending on whether or not they had previously been passaged in mice. For all Listeria spp. the BALB/c mice were more susceptible than the C57BL/6 mice, by (10-20)-fold for L. monocytogenes and $L$. ivanovii and by at least (24)-fold for the other species.

\section{Course of infection in mouse liver}

Two strains of $L$. monocytogenes and one each of the other species were selected to study the course of infection in livers of both mouse strains, and two distinct patterns emerged (fig. 1). For both strains of $L$. monocytogenes and for $L$. ivanovii, low recoveries of bacteria $6 \mathrm{~h}$ after infection were followed by (500-10 000)-fold increases during the next 30 $50 \mathrm{~h}$. Thereafter, there was a more or less rapid decline in viable counts. As defined by LD50 values (table), virulence correlated with more abundant growth in the liver in relation to the inoculum dose (fig. 1) and, for L. ivanovii as for L. monocytogenes (Cheers et al., 1978), the more resistant host showed earlier onset of acquired immunity as well as lower peak levels of bacteria. By contrast, there was no apparent growth of bacteria in livers of mice infected intravenously with L. innocua, L. welshimeri or L. seeligeri. Rather, from initially
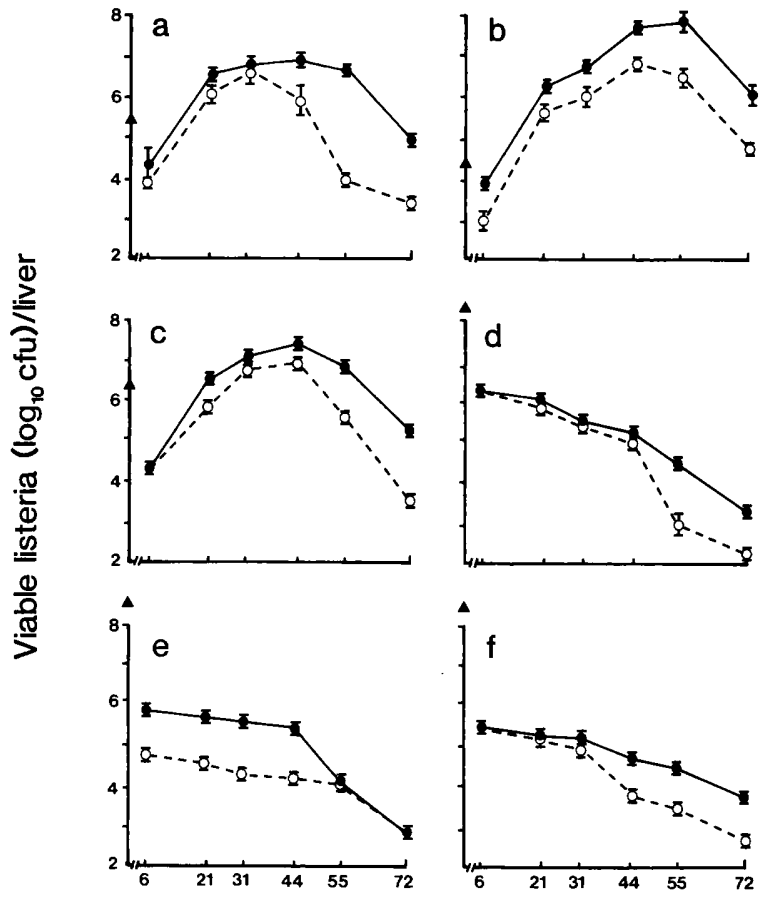

Time after infection $(h)$

Fig. 1. Course of infection by Listeria species in livers of C57BL/6 (०-0) and BALB/c (•-•) mice: (a) L. monocytogenes SLCC 2540; (b) L. monocytogenes AB1; (c) L. ivanovii W5379; (d) L. innocua AB6; (e) L. welshimeri CIP 8149 ; (f) L. seeligeri AB2. Bar represents 1 SEM of counts from four or five mice per group (Hodge and Seed, 1977); $\boldsymbol{\Delta}=$ bacterial inoculum.

low yields 6 h after infection, viable counts declined, at first gradually and then, in some instances and after $\geqslant 40 \mathrm{~h}$, apparently more steeply. In accordance with expectations from the LD50 values, fewer organisms were recovered from $\mathrm{C} 57 \mathrm{BL} / 6$ than from BALB/c mice. However, apart from the infections with $L$. welshimeri, the differences were not marked until late in infection.

\section{Histopathological evaluation}

Gross examination revealed small white foci in livers from mice infected with $L$. monocytogenes and L. ivanovii, but not after infection with the other listeriae. Microscopic appearances (fig. 2) also distinguished infections with the pathogens from those with the non-pathogens, but no clearcut differences were noted between the two mouse strains. Mice infected with $L$. monocytogenes and $L$. ivanovii developed an intense focal inflammatory response, as previously noted for $L$. monocytogenes (Mandel and Cheers, 1980). Sparse infiltrations of 
Table. Identity, sources, haemolytic and biochemical properties, and LD50 values of Listeria strains

\begin{tabular}{|c|c|c|c|c|c|c|c|c|c|c|}
\hline \multirow[b]{2}{*}{ Listeria spp. } & \multirow[b]{2}{*}{$\begin{array}{l}\text { Strain designation } \\
\text { (obtained from)* }\end{array}$} & \multirow[b]{2}{*}{ Serotype } & \multirow{2}{*}{$\begin{array}{l}\text { Haemolysis on } \\
\text { sheep blood agar } \\
\text { (zone in mm) }\end{array}$} & \multicolumn{2}{|c|}{ CAMP test $†$ with } & \multicolumn{3}{|c|}{ Acid production from } & \multicolumn{2}{|c|}{$\operatorname{LD} 50\left(\mathrm{cfu} \times 10^{6}\right)$} \\
\hline & & & & S. aureus & R. equi & D-xylose & L-rhamnose & $\begin{array}{l}\alpha \text {-methyl D- } \\
\text { mannoside }\end{array}$ & $\mathrm{C} 57 \mathrm{BL} / 6$ & BALB $/ \mathrm{c}$ \\
\hline \multirow[t]{5}{*}{ L. monocytogenes } & $\begin{array}{l}\text { NCTC 7973(T) } \\
\text { (ATCC 19111) }\end{array}$ & $1 / 2 a$ & $0 \cdot 8-1 \cdot 0$ & + & - & - & + & + & $4 \cdot 4$ & 0.44 \\
\hline & SLCC 2540(S)‡ & $3 b$ & $0.5-0.8$ & + & - & - & + & + & $6 \cdot 2$ & 0.57 \\
\hline & NCTC $10527(\mathrm{~S})$ & $4 b$ & $0.5-0.8$ & + & - & - & + & + & $3 \cdot 0$ & $0 \cdot 14$ \\
\hline & AB3 (L) & $4 b$ & $0.5-0.8$ & + & - & - & + & + & $1 \cdot 7$ & $0 \cdot 10$ \\
\hline & $\mathrm{AB} 1(\mathrm{P}) \ddagger$ & $1 / 2 \mathrm{a}$ & $0 \cdot 8-1 \cdot 0$ & + & - & - & + & + & 0.76 & 0.035 \\
\hline \multirow[t]{3}{*}{ L. ivanovii } & $\begin{array}{l}\text { ATCC 19119(S) } \\
\text { (SLCC 2379) }\end{array}$ & 5 & $1 \cdot 0-1 \cdot 2$ & - & + & + & - & - & 20 & 0.90 \\
\hline & NCTC $1100(T)$ & 5 & $1 \cdot 0-1 \cdot 2$ & - & + & + & - & - & 20 & 0.95 \\
\hline & W $5379(T) \ddagger$ & 5 & $1 \cdot 0-1 \cdot 2$ & - & + & + & - & - & 40 & $2 \cdot 6$ \\
\hline \multirow[t]{2}{*}{ L. innocua } & NCTC $11299(S)$ & $6 a$ & 0 & - & - & - & + & + & $>1000$ & 330 \\
\hline & AB6 $(L) \ddagger$ & $6 b$ & 0 & - & - & - & + & + & $>1000$ & 290 \\
\hline L. welshimeri & CIP 8149 (R) $\ddagger$ & $6 b$ & 0 & - & - & + & - & + & $>1000$ & 240 \\
\hline \multirow[t]{2}{*}{ L. seeligeri } & CIP $100100(R)$ & $1 / 2 b$ & $0 \cdot 4-0.6$ & + & - & + & - & - & $>1000$ & 420 \\
\hline & $\mathrm{AB} 2(\mathrm{~L}) \ddagger$ & 6 & $0.4-0.6$ & + & - & + & - & - & $>1000$ & 470 \\
\hline
\end{tabular}

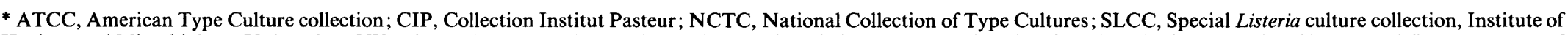
Hygiene and Microbiology, University of Würzburg; AB1, AB2, AB3 and AB6, isolates from infected neonate (AB1) or from healthy faecal carriers (AB2, 3 and 6), Department of Bacteriology, University of Aberdeen; T, Dr A. G. Taylor; S, Professor H. P. R. Seeliger; R, Dr J. Rocourt; L, Dr R. J. Lamont; P, Professor R. Postlethwaite.

$\dagger$ CAMP test, accentuation of haemolysis on sheep-blood agar in the vicinity of $S$. aureus or $R$. equi.

$\ddagger$ Strains used to study course of infection in mouse liver. 

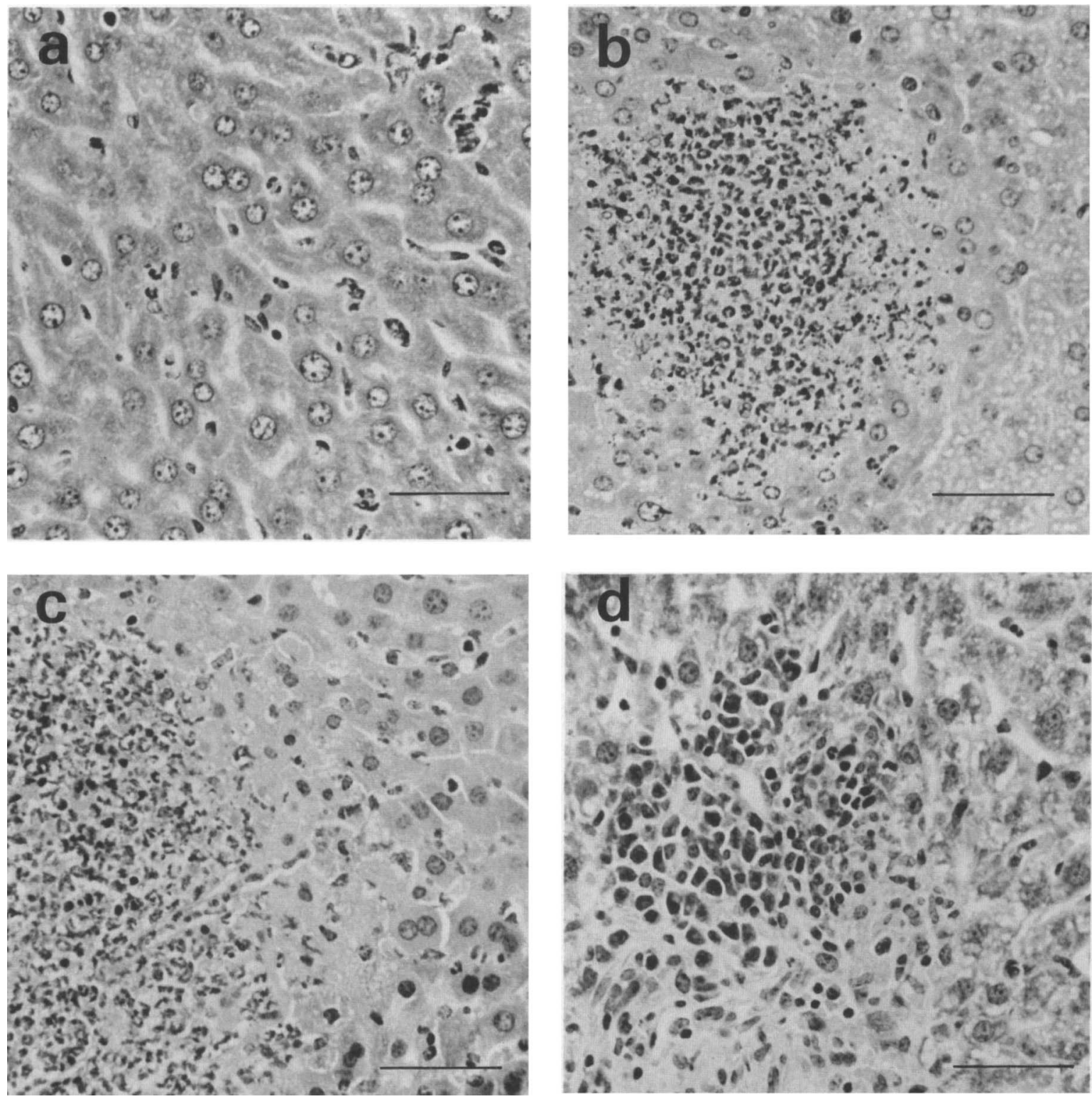

Fig. 2. Histology of mouse livers infected by Listeria spp. at indicated hours after infection: (a) L. seeligeri AB2, $6 \mathrm{~h}-\mathrm{mild} \mathrm{PMN}$ infiltration; (b) L. monocytogenes SLCC 2540, $30 \mathrm{~h}$-micro-abscess and hepatocyte degeneration; (c) L. ivanovii W $5379,30 \mathrm{~h}-$ micro-abscess and hepatocyte degeneration; (d) L. ivanovii W 5379, 9 days-residual granuloma. (Haematoxylin and eosin; bar $=50 \mu \mathrm{m})$.

liver sinusoids with PMNs were seen $6 \mathrm{~h}$ after infection and these developed into randomly distributed focal collections by $21 \mathrm{~h}$ and into large micro-abscesses by $31-72 \mathrm{~h}$. Both PMNs and surrounding hepatocytes began to degenerate from $21 \mathrm{~h}$ and areas of hepatocyte necrosis were prominent around degenerate micro-abscesses by 44 $55 \mathrm{~h}$. Macrophages accumulated peripherally 31$44 \mathrm{~h}$ after infection and, by 55-72 h, inflammatory foci became granulomatous in character, consisting predominantly of MPs and lymphocytes with central degenerate PMNs. Granulomas were still present 9 days after infection, being composed of MPs, lymphocytes, plasma cells, fibroblasts and occasional PMNs. By contrast with these florid histological manifestations of infection, mice infected with $L$. innocua, $L$. welshimeri and $L$. seeligeri showed no consistent abnormality apart from mild 
infiltration with PMNs $6 \mathrm{~h}$ after infection and this resolved within $21 \mathrm{~h}$. Control mice given diluent alone showed no significant abnormality.

Gram-positive bacilli were seen in livers of mice of both strains after infection with all Listeria spp. except $L$. welshimeri. In infections with the almost avirulent bacteria, they were present only in resident Kupffer cells, in small numbers, and up to $31 \mathrm{~h}$ after infection ( $72 \mathrm{~h}$ for L. innocua). By contrast, and additionally, clusters of apparently replicating bacteria were seen in the developing inflammatory foci of livers infected with the virulent species $L$. monocytogenes and $L$. ivanovii and, in the more severe infections, also inside some hepatocytes.

\section{Discussion}

These experiments extend earlier findings (Cheers et al., 1978; Mitsuyama et al., 1978; Mandel and Cheers, 1980; Rocourt et al., 1983a; von Koenig et al., 1983) by relating virulence and histological features for representative strains of all five Listeria spp., and by showing that L. ivanovii, like $L$. monocytogenes, is highly pathogenic for both C57BL/6 and BALB/c mice, but that $L$. innocua, $L$. welshimeri and $L$. seeligeri are not. Furthermore, C57BL/6 mice were more resistant than BALB/c mice to infection by $L$. ivanovii, as previously reported and confirmed here for $L$. monocytogenes (Kongshavn, 1985). Differential sensitivity of the two mouse strains to the less pathogenic listeriae was less clear-cut than for the virulent bacteria. Although the weak pathogens appeared not to grow in the livers of either strain of mouse, they were cultured in consistently greater numbers from livers of BALB/c than of C57BL/6 mice, and LD50 values were consistently lower in BALB/c mice.

A precise immunochemical basis for serotypic differences in mouse virulence amongst listeriae is not established. Variations in sugar substituents of cell-wall teichoic acids and possibly lipoteichoic acids (Seeliger and Jones, 1986), that appear partly to determine $\mathrm{O}$-antigenic specificities, probably do not account for the serotypic differences in virulence amongst strains of L. monocytogenes reported here and by others (Rocourt et al., 1983a; von Koenig et al., 1983). Thus, listeriae of high and low virulence can have such $\mathrm{O}$-antigen specificities in common, as exemplified by the existence of serotype 3 strains both of the virulent $L$. monocytogenes and of the largely avirulent $L$. innocua (Knorz and Hof, 1986), and similarly by the serotype $1 / 2$ strains of both $L$. monocytogenes and $L$. seeligeri examined in this study. Conversely, strains with similar (high or low) levels of virulence may have different $\mathrm{O}$-antigenic specificities, as represented in this study by the highly virulent serotypes $4 \mathrm{~b}$ (AB3) and $3 \mathrm{~b}$ (SLCC 2540 ) of $L$. monocytogenes and the almost nonpathogenic $L$. seeligeri serotypes $1 / 2 \mathrm{~b}$ (CIP 100100) and 6(AB2). Other structural components of $L$. monocytogenes, including a lipopolysaccharide, endotoxin-like component and a high molecular weight, carbohydrate-containing, immunosuppressive agent have been studied as immunomodulating agents (Galsworthy, 1984) but not as inter- or intraspecies-related virulence determinants. A virulence-determining role for cell-wall proteins was recently suggested in a study of smooth and rough variants of haemolytic type $1 / 2 \mathrm{a}$ strains of L. monocytogenes (Hof and Chatzipanagiotou, 1987), despite the demonstration by Lamont et al. (1986) of rather similar profiles, in SDS-PAGE gels, of whole-cell polypeptides from serotypes of all species of $L$. monocytogenes sensu lato. Whether protein differences might explain the minor intratypic variations in virulence amongst strains of L. ivanovii (type 5) reported here and by Rocourt et al. (1983a) remains to be shown. The reason for the higher virulence of our type $1 / 2$ a $L$. monocytogenes strain AB1, compared with strain NCTC 7973, is not clear; but enhancement of virulence by mouse passage is well known (von Koenig et al., 1983). It may also be relevant that $L$. monocytogenes NCTC 7973 was amongst the non-persisting strains in the study of Kaufmann (1984). The predominance of serotypes $1 / 2 \mathrm{a}$ and $4 \mathrm{~b}$ in natural human and animal infections (Ralovich, 1984) is as yet unexplained.

Histological examination showed no qualitative differences between the two mouse strains in the evolution of the hepatic infection, whether induced by L. ivanovii or L. monocytogenes. Mandel and Cheers (1980) described quantitative differences in the development of inflammatory foci in the livers of $\mathrm{C} 57 \mathrm{BL} / 10$ and $\mathrm{BALB} / \mathrm{c}$ mice as a consequence of infection with high, but not low, doses of L. monocytogenes. Such differences were not seen with the lower doses used here and our results agreed with aspects of previous histological descriptions for $L$. monocytogenes infections in single strains of mice (North, 1970; Tatsukawa et al., 1979; Mandel and Cheers, 1980; von Koenig et al., 1983), in which, overall, early pyogenic foci with abundant bacilli and developing hepatocyte necrosis were replaced by MP-rich granulomas devoid of bacilli. These histological features accord with the capacity of both bacterial species to induce homotypic or heterotypic protective immunity (Seeliger et al., 1982; von Koenig et al., 1983) and it seems likely that the highly virulent strains of 
L. monocytogenes SLCC 2540 (type 3b) and AB1 (type 1/2a) and of L. ivanovii W5379 (type 5) belong to the immunologically-active persisting category defined by Kaufmann (1984).

Genetic differences in innate resistance to L. monocytogenes, which distinguish C57BL/6 from $\mathrm{A} / \mathrm{J}$ mice, have been attributed mainly to a deficiency in the latter of the C5 component of complement (Gervais et al., 1984; Czuprynski et al., 1985) with consequent impairment in the accumulation of inflammatory cells during the second stage of infection. However, to account for different degrees of bacterial growth in susceptible mice, Gervais et al. (1984) postulated the expression of a second gene. Such a gene might account for the relative susceptibility of C5-sufficient BALB/c mice to both L. monocytogenes and L. ivanovii; and, indeed, inflammatory peritoneal MPs from C57BL/ 6 mice have superior listericidal capacity compared with those from BALB/c mice (Wood et al., 1986) but not with those from $\mathrm{A} / \mathrm{J}$ mice (Gervais et al., 1986). Also relevant is the membrane-derived monocytosis-producing activity (MPA) of L. monocytogenes, to which $\mathrm{A} / \mathrm{J}$ mice do not respond (Galsworthy, 1984) and which is not produced by L. innocua (Galsworthy, 1987), and the variable monocytopoietic responses of different mouse strains to soluble factors produced by the host during inflammatory responses (Wing et al., 1985).

Apart from a slight and transient infiltration with PMNs, there was no other morphological response by either host in the livers infected by the three less pathogenic listeriae. Although apparently at variance with the demonstration by Patoćka et al. (1979) and Manev et al. (1981) of intracerebral and intra-oesophageal pathogenicity of $L$. innocua for suckling mice and for adult mice and rats, respectively, this finding accords with the failure of von Koenig et al. (1983) to demonstrate a granulomatous response in mouse liver. However, these workers were able to induce a weak protective immunity against a serotype $4 \mathrm{~b}$ strain of L. monocytogenes with large doses of L. innocua serotype $6 \mathrm{~b}$. By contrast, avirulent variants of L. monocytogenes (Berche et al., 1987) and a recently-described serotype 3 strain of $L$. innocua (Knorz and Hof, 1986) were entirely lacking in protective immunogenicity, though capable of boosting a pre-existing immunity. Whilst histological examination may have limited sensitivity for the detection of acquired cell-mediated immunity, these seeming discrepancies call into question the possible immunopathogenic significance of the consistent, but inadequately-evaluated, differences between the lethality figures obtained with the two different strains of mice for all three of the weakly pathogenic listeriae, as of the more variable differences in bacterial recoveries after $6 \mathrm{~h}$ of infection.

Listeriae are not killed by mouse serum and the rapid decline in viable bacteria during the first $6 \mathrm{~h}$ of liver infection with $L$. monocytogenes is generally attributed to the bactericidal action of resident Kupffer cells. This might also hold for the weakly virulent listeriae studied here, although the proportion of inoculum bacteria taken up by the liver, and thus the absolute amount of intra-hepatic killing, was not determined. Moreover the fate of such bacteria in cultured MPs has not been adequately studied (Watson and Lavizzo, 1973) and, in vivo, the eradication of a serotype $1 / 2 \mathrm{a}$ strain of $L$. seeligeri and of a serotype 3 a strain of $L$. innocua was little affected by prior elimination of MPs (Hof and Chatzipanagiotou, 1987; Knorz and Hof, 1986). It is probably significant that, whilst L. monocytogenes and L. ivanovii were recently shown to invade and grow in a cultured line of human colon carcinoma cells, $L$. innocua, $L$. welshimeri and $L$. seeligeri were unable even to invade these cells (Gaillard et al., 1987). For L. monocytogenes, early in-vivo decline is not always great (Newborg and North, 1980) and cultured MPs showed substantial inhibitory activity only if previously activated by inflammatory or immunological stimuli (Godfrey et al., 1983; Czuprynski et al., 1984; Krishnan and Humphrey, 1986). Indeed, immunologically naïve Kupffer cells (Krishnan and Humphrey, 1986) and otherwise non-activated MPs (Godfrey et al. 1983; Kathariou et al., 1987a) permitted early growth of $L$. monocytogenes in vitro, and peritoneal MPs from BALB/c mice supported bacterial growth better than those from C57BL/6 mice. Moreover Kupffer cells failed to generate significant amounts of hydrogen peroxide during the course of murine listeriosis (Lepay et al., 1985), although killing of L. monocytogenes, especially of organisms in the logarithmic phase of growth, may not necessarily occur by oxidative mechanisms (Godfrey and Wilder, 1984; Bortolussi et al., 1987). Whether non-oxidative mechanisms and cells other than Kupffer cells are important in early listerial killing needs further investigation. Possible roles for NK cells early in infection (Kearns and Leu, 1984) and of cytotoxic Lyt $2^{+}$immune T cells later (Kaufmann et al., 1986) have been suggested, although NK activity appeared not to account for genetically-determined innate resistance (Skamene and Kongshavn, 1983) and was not stimulated by an avirulent strain of $L$. monocytogenes (Kearns and Leu, 1984). 
The role of PMNs in murine listeriosis, despite their early prominence, is generally considered irrelevant (North, 1970; Cheers and McKenzie, 1978; Mitsuyama et al., 1978; Tatsukawa et al., 1979). North (1970), but not Mandel and Cheers (1980), showed that most bacteria in the liver foci of $24 \mathrm{~h}$-infected mice were in PMNs, some being extra-cellular and others in parenchymal cells; but bacterial killing began only with the later appearance of bactericidal inflammatory MPs. However, Czuprynski et al. (1984), using opsonised bacteria, showed that inflammatory peritoneal PMNs killed $L$. monocytogenes in vitro better than did MPs, and those from $\mathrm{C} 57 / \mathrm{BL} / 6$ mice somewhat more effectively than those from $\mathrm{A} / \mathrm{J}$ mice (Czuprynski et al., 1985). Nevertheless, C57BL/6J MPs were not intrinsically more listericidal than those from $A / J$ mice (Gervais et al., 1986). Whether non-persisting strains of Listeria (Kaufmann, 1984) are especially susceptible to killing by $\mathrm{PMNs}$ remains to be shown for, if so, any consequent impairment of antigen presentation could affect the demonstrably deficient development of cell-mediated immunity. As confirmed by MacGowan et al. (1983), cultured human PMNs are strikingly listericidal.

The use of bacterial variants and geneticallydefined hosts permits increased understanding of the pathogenesis of infection, and this study emphasises the importance of early events and areas of present uncertainty. However, natural variants are of undefined genotype and may differ in ways which are neither recognised nor understood. Recent studies with the technique of transpo-

\section{REFERENCES}

Berche P, Gaillard J L, Sansonetti P J 1987 Intracellular growth of Listeria monocytogenes as a prerequisite for in-vivo induction of T cell-mediated immunity. Journal of Immunology 138: 2266-2271.

Bortolussi R et al. 1984 Host defense mechanisms to perinatal and neonatal Listeria monocytogenes infection. Survey and Synthesis of Pathology Research 3: 311-332.

Bortolussi R, Vandenbroucke-Grauls CMJE, van Asbeck B S, Verhoef J 1987 Relationship of bacterial growth phase to killing of Listeria monocytogenes by oxidative agents generated by neutrophils and enzyme systems. Infection and Immunity 55: 3197-3203.

Cheers C, McKenzie I F C 1978 Resistance and susceptibility of mice to bacterial infection: genetics of listeriosis. Infection and Immunity 19: 755-762.

Cheers C, McKenzie I F C, Pavlov H, Waid C, York J 1978 Resistance and susceptibility of mice to bacterial infection : course of listeriosis in resistant or susceptible mice. Infection and Immunity 19: 763-770.

Christie R, Atkins N E, Munch-Petersen E 1944 A note on a lytic phenomenon shown by group B streptococci. Australian son mutagenesis (Gaillard et al., 1986; Kathariou et al., 1987b; Mengaud et al., 1987), which can eliminate such uncertainties, have discounted the importance of listerial catalase and re-emphasised the role of listerial haemolysin as a major virulence determinant. It could operate early in the initial encounter with host phagocytes (Kingdon and Sword, 1970), thus permitting escape from the phagocytic vacuole and intracytoplasmic bacterial growth which, in turn, is required for the induction of T cell-mediated immunity (Berche et al., 1987). The heterogeneity of listerial haemolysins (Parrisius et al., 1986) could readily explain the observed differences in CAMP test results between strains of $L$. monocytogenes and those of $L$. ivanovii. The apparent paradox that strains of $L$. monocytogenes and $L$. seeligeri show similar CAMP test reactions, but vary greatly in virulence, may reflect an inability of $L$. seeligeri to produce a virulence-related $\alpha$ haemolysin, whilst sharing with $L$. monocytogenes the capacity to produce an oxygen-stable haemolysin, responsible for the visible zone of $\beta$-haemolysis on a blood-agar plate. Whether listerial lipolysin might contribute to the PMN and hepatocyte necrosis described here, as shown for cultured MPs by Watson and Lavizzo (1973), remains to be shown. Further molecular genetic studies will undoubtedly add to our understanding of these and other virulence determinants of this bacterial genus.

We thank the Scottish Home and Health Department for financial support and Mrs Betty Smith for secretarial help.
Journal of Experimental Biology and Medical Science 22: 197-200.

Czuprynski C J, Canono B P, Henson P M, Campbell P A 1985 Genetically determined resistance to listeriosis is associated with increased accumulation of inflammatory neutrophils and macrophages which have enhanced listericidal activity. Immunology 55: 511-518.

Czuprynski C J, Henson P M, Campbell PA 1984 Killing of Listeria monocytogenes by inflammatory neutrophils and mononuclear phagocytes from immune and nonimmune mice. Journal of Leukocyte Biology 35: 193-208.

Fraser G 1962 A plate method for the rapid identification of Listeria (Erysipelothrix) monocytogenes. Veterinary Record 74: $50-51$.

Gaillard J L, Berche P, Mounier J, Richard S, Sansonetti P 1987 Penetration of Listeria monocytogenes into the host : a crucial step of the infectious process. Annales de Microbiologie (Institut Pasteur) 138: 259-264.

Gaillard J L, Berche P, Sansonetti P 1986 Transposon mutagenesis as a tool to study the role of hemolysin in the virulence of Listeria monocytogenes. Infection and Immunity 52: $50-55$.

Galsworthy S B 1984 Immunomodulation by surface components 
of Listeria monocytogenes: a review. Clinical and Investigative Medicine 7: 223-227.

Galsworthy S B 1987 Role of the cell surface in virulence of Listeria monocytogenes. Annales de Microbiologie (Institut Pasteur) 138: 273-276.

Gervais F, Morris-Hooke A, Tran T A, Skamene E 1986 Analysis of macrophage bactericidal function in genetically resistant and susceptible mice by using the temperaturesensitive mutant of Listeria monocytogenes. Infection and Immunity 54: 315-321.

Gervais F, Stevenson M, Skamene E 1984 Genetic control of resistance to Listeria monocytogenes: regulation of leukocyte inflammatory responses by the $\mathrm{Hc}$ locus. Journal of Immunology 132: 2078-2083.

Godfrey R W, Horton P G, Wilder M S 1983 Time course of antilisterial activity by immunologically activated murine peritoneal macrophages. Infection and Immunity 39: 532 539.

Godfrey R W, Wilder M S 1984 Relationships between oxidative metabolism, macrophage activation, and antilisterial activity. Journal of Leukocyte Biology 36: 533-543.

Groves R D, Welshimer H J 1977 Separation of pathogenic from apathogenic Listeria monocytogenes by three in-vitro reactions. Journal of Clinical Microbiology 5 : 559-563.

Hodge S E, Seed M L 1977 Statistics and Probability, 2nd edn. Blackie, Glasgow, and Chambers, Edinburgh, pp 150-163.

Hof H, Chatzipanagiotou S 1987 The role of surface structures of Listeria spp. for pathogenicity. Annales de Microbiologie (Institut Pasteur) 138: 268-273.

Kathariou S, Köhler S, Kuhn M, Goebel W 1987 a Identification of the virulence components of Listeria monocytogenes by transposon (Tn 916) mutagenesis. Annales de Microbiologie (Institut Pasteur) 138: 256-258.

Kathariou S, Metz P, Hof H, Goebel W $1987 b$ Tn 916-induced mutations in the hemolysin determinant affecting virulence of Listeria monocytogenes. Journal of Bacteriology 169 : 12911297.

Kaufmann S H E 1984 Acquired resistance to facultative intracellular bacteria: relationship between persistence, cross-reactivity at the T-cell level, and capacity to stimulate cellular immunity of different Listeria strains. Infection and Immunity 45: 234-241.

Kaufmann S H E, Hug E, de Libero G 1986 Listeria monocytogenes-reactive $\mathrm{T}$ lymphocyte clones with cytolytic activity against infected target cells. Journal of Experimental Medicine 164: 363-368.

Kearns R J, Leu R W 1984 Modulation of natural killer activity in mice following infection with Listeria monocytogenes. Cellular Immunology 84: 361-371

Kingdon G C, Sword C P 1970 Effects of Listeria monocytogenes hemolysin on phagocytic cells and lysosomes. Infection and Immunity 1: 356-362.

Knorz W, Hof H 1986 Pathogenicity of Listeriae. Immunität und Infektion 2: 76-80

Kongshavn P A L 1985 Genetic control of murine listeriosis expressed in the macrophage response. Immunology Letters 11: 181-188.

Krishnan V L, Humphrey J H 1986 Inhibition of growth of Listeria monocytogenes in vitro by immunologically activated mouse resident macrophages. British Journal of Experimental Pathology 67: 809-819.

Lamont R J, Petrie D T, Melvin W T, Postlethwaite R 1986 An investigation of the taxonomy of Listeria species by comparison of electrophoretic protein patterns. In: Courtieu A-L et al. (eds) Listeriose Listeria Listeriosis 1985-86, Proceedings of the 9th International Symposium on the Problems of Listeriosis, Université de Nantes, pp 41-46.
Lepay D A, Steinman R M, Nathan C F, Murray H W, Cohn Z A 1985 Liver macrophages in murine listeriosis. Cellmediated immunity is correlated with an influx of macrophages capable of generating reactive oxygen intermediates. Journal of Experimental Medicine 161 : 1503-1512.

MacGowan A P, Peterson P K, Keane W, Quie P G 1983 Human peritoneal macrophage phagocytic, killing and chemiluminescent responses to opsonized Listeria monocytogenes. Infection and Immunity 40: 440-443.

Mandel T E, Cheers C 1980 Resistance and susceptibility of mice to bacterial infection: histopathology of listeriosis in resistant and susceptible strains. Infection and Immunity 30 : $851-861$

Manev H, Stoyanov D, Makeva M 1981 Study of the pathogenicity of strain Listeria innocua for experimental animals infected orally. Fifth Congress of Microbiology, Varna 1981, Part II. Publishing House of the Bulgarian Academy of Sciences, Sofia, pp 141-146.

Mengaud J, Chenevert J, Geoffroy C, Gaillard J-L, Cossart P 1987 Identification of the structural gene encoding the SHactivated hemolysin of Listeria monocytogenes: listeriolysin $\mathrm{O}$ is homologous to streptolysin $\mathrm{O}$ and pneumolysin. Infection and Immunity 55: 3225-3227.

Miles A A, Misra S S, Irwin J O 1938 The estimation of the bactericidal power of the blood. Journal of Hygiene 38: 732749.

Mitsuyama M, Takeya K, Nomoto K, Shimotori S 1978 Three phases of phagocyte contribution to resistance against Listeria monocytogenes. Journal of General Microbiology 106: 165-171.

Newborg M F, North R J 1980 On the mechanism of T cellindependent anti-listeria resistance in nude mice. Journal of Immunology 124: 571-576.

North R J 1970 The relative importance of blood monocytes and fixed macrophages to the expression of cell-mediated immunity to infection. Journal of Experimental Medicine 132: $521-534$.

North R J 1981 Immunity of Listeria monocytogenes. In: Nahmias A J, O'Reilly R J (eds) Immunology of human infection Part 1: Bacteria, Mycoplasmae, Chlamydiae and Fungi. Plenum Medical Book Company, New York and London, pp 201-219.

Parrisius J, Bhakdi S, Roth M, Tranum-Jensen J, Goebel W, Seeliger H P R 1986 Production of listeriolysin by betahaemolytic strains of Listeria monocytogenes. Infection and Immunity 51 : 314-319.

Patoćka F, Menčkova E, Seeliger H P R, Jirásek A 1979 Neurotropic activity of a strain of Listeria innocua for suckling mice. Zentralblatt für Bakteriologie Mikrobiologie und Hygiene 1 Abteilung Originale A 243: 490-498.

Ralovich B 1984 Listeriosis research: present situation and perspective. Akadémiai Kiadó, Budapest.

Reed L J, Muench H 1938 A simple method of estimating fifty percent endpoints. American Journal of Hygiene 27: 493497.

Rocourt J, Alonso J-M, Seeliger H P R 1983a Virulence comparée des cinq groupes génomiques de Listeria monocytogenes (sensu lato). Annales de Microbiologie (Institut Pasteur) 134A : 359-364.

Rocourt J, Grimont F, Grimont P A D, Seeliger H P R 1982 DNA relatedness among serovars of Listeria monocytogenes sensu lato. Current Microbiology 7: 383-388.

Rocourt J, Schrettenbrunner A, Seeliger H P R $1983 b$ Différenciation biochimique des groupes génomiques de Listeria monocytogenes (sensu lato). Annales de Microbiologie (Institut Pasteur) 134A : 65-71.

Seeliger H P R, Höhne K 1979 Serotyping of Listeria 
monocytogenes and related species. In: Bergan $\mathrm{T}$, Norris $\mathrm{J}$ $R$ (eds) Methods in Microbiology 13. Academic Press, London, pp 31-49.

Seeliger H P R, Jones D 1986 Genus Listeria Pirie 1940, 383 AL. In: Sneath P H A et al. (eds) Bergey's Manual of systematic bacteriology vol 2. Williams and Wilkins, Baltimore, pp 1235-1245.

Seeliger H P R, Schrettenbrunner A, Pongratz G, Hof H 1982 Special position of strongly haemolytic strains of the genus Listeria. Zentralblatt für Bakteriologie Mikrobiologie und Hygiene 1 Abteilung Originale A 252: 176-190 (in German).

Skamene E, Kongshavn P A L 1983 Cellular mechanisms of resistance to Listeria monocytogenes In: Eisenstein $\mathrm{T} \mathrm{K}$ et al. (eds) Host resistance to intracellular pathogens. Advances in Experimental Medicine and Biology 162. Plenum Publishing Corporation, New York, pp 217-225.

Tatsukawa K, Mitsuyama M, Takeya K, Nomoto K 1979 Differing contribution of polymorphonuclear cells and macrophages to protection of mice against Listeria mono- cytogenes and Pseudomonas aeruginosa. Journal of General Microbiology 115: 161-166.

von Koenig C H W, Heymer B, Hof H, Finger H 1983 Course of infection and development of immunity in experimental infection of mice with Listeria serotypes. Infection and Immunity 40: 1170-1177.

Watson B B, Lavizzo J C 1973 Intracellular antigens from Listeria monocytogenes. II. Cytotoxicity of hemolytic and lipolytic antigens of Listeria for cultured mouse macrophages. Infection and Immunity 7: 753-758.

Wing E J, Barczynski L C, Waheed A, Shadduck R K 1985 Effect of Listeria monocytogenes infection on serum levels of colony-stimulating factor and number of progenitor cells in immune and nonimmune mice. Infection and Immunity 49 : 325-328.

Wood P R, Spanidis V, Frangos K, Cheers C 1986 The in vitro bactericidal activity of peritoneal and spleen cells from Listeria-resistant and -susceptible mouse strains. Cellular Immunology 99: 160-169. 